\title{
Medical student involvement in health policy roles
}

This article was published in the following Dove Press journal:

Advances in Medical Education and Practice

6 November 2017

Number of times this article has been viewed

\section{Bassit Malik' \\ Utkarsh Ojha' \\ Hassan Khan' \\ Farzana Begum² \\ Harun Khan' \\ Qasim Malik ${ }^{3}$}

'School of Medicine, Imperial College London, London, UK; ${ }^{2}$ Barts and the London School of Medicine and Dentistry, London, UK; ${ }^{3}$ Heart of England NHS Foundation Trust, Birmingham, UK
Correspondence: Bassit Malik 32 Swanshurst Lane, Moseley, Birmingham BI 3 0AJ, UK

Tel +447769688248

Email Bassit.malikI2@imperial.ac.uk
Objectives: A teaching curriculum in health policy may be well established in medical school; however, an emphasis on applying taught principles via participation in health policy roles is less defined. We undertook a study to explore medical student participation in health policy roles.

Design and setting: An anonymous online survey via convenience sampling was conducted in the UK.

Participants: A total of 112 students from six medical schools participated in the study.

Outcome measures: The outcome measures were as follows: medical students' beliefs about their current knowledge of health policy and their desire to learn more; their current, past and future involvement in a health policy role, and perceived barriers to involvement.

Results: Forty-seven percent of participants reported previous teaching on health policy, with the majority scoring themselves 2 out of 5 for knowledge about the topic (38\%). Seventy-seven percent of participants expressed a desire to be taught health policy while $73 \%$ agreed with compulsory teaching. Ninety-six percent of participants reported no current or previous activity in a health policy role, with $61 \%$ willing to undertake a role in the future. The three main barriers to student involvement were: a lack of knowledge about health policy (57\%), an unawareness of opportunities available (56\%), and a lack of time (43\%).

Conclusion: In addition to already established teaching programs within medical school, implementation of community-based experiences could improve knowledge of health policy, while providing an opportunity for students to gain experience in health policy committee roles. Keywords: medical curriculum, policy committee, service learning

\section{Introduction}

The World Health Organization (WHO) defines health policy as "decisions, plans, and actions that are undertaken to achieve specific health care goals within a society [...]. It outlines priorities and the expected roles of different groups; and it builds consensus and informs people." Individuals involved in health policy decisions have a powerful opportunity to represent the voice of an unheard community. The involvement of public and patients' voice is key to greater accountability and democratic decision making. ${ }^{2}$ In cases where this input is unheard, medical students can bring the public voice to the forefront in decision making.

Although patients may be represented in decisions that affect their care, in situations where this is not the case, medical students may act as advocates for patients' views. The holistic approach in medical school towards patient management can reveal areas for betterment of care. As the General Medical Council (GMC) outlines, ${ }^{3}$ medical students should undertake the exercise of documenting a "patient journey" by following a patient across their interactions with the health service in primary, secondary and 
often tertiary care. Through our own reflections, this approach to patient management has two major benefits: the first is in our ability to see how continuity affects patient experience and the second is being able to understand the patient's own thoughts about this process.

The insights garnered by medical students in this process will be of value for a number of reasons. The most important asset is generating this holistic perspective, which qualified doctors may not be able to achieve due to their workload and time constraints. Secondly, the numerary power this process has is significant; with the reflective views of each individual in a year group of medical school, common areas of development that can improve patient experience would be identified and can be developed upon. Thirdly, medical students could assist by using their knowledge of health processes to help reform the system. Even as a medical student, being the link between patient and policy maker is a key position that carries benefits for the entire health policy-making process and the individuals involved.

Patients report high rates of satisfaction having participated in a "follow the patient" scheme, ${ }^{4}$ and as students among those who have also participated in a similar exercise, we can see the value of the experience and its application. However, this does not necessarily represent interest in health policy as a medical student body.

Throughout the junior doctor contract changes in 2016, the way in which the medical student cohort united as a body to voice their opinions of the contract was particularly striking. Over 7,000 medical students signed a British Medical Association (BMA) pledge, citing concerns over safety, quality and fairness. ${ }^{5}$ The large numbers of individuals present at industrial action against the contract and the research into student opinion on academic forums ${ }^{6}$ are signs of student interest in health policy. Students can bring unique viewpoints to health policy discussions and have a shared interest in the topic; both are key factors for the core curriculum in which health policy is explored at medical school. A brief Internet search highlighted comprehensive research undertaken by the Royal College of General Practitioners (RCGP) into what should constitute a curriculum in health inequalities in the UK at undergraduate medical school. ${ }^{7}$ The findings of this study were based largely upon the expert input of medical educators and looked at the topic from a pedagogical perspective; presenting the findings in the form of learning outcomes suitable for establishing a medical school curriculum. Health policyrelated learning outcomes, as well as the GMC's outcomes for graduates, are included in this; one example being "discuss the principles underlying the development of health and health service policy, including issues relating to health economics and equity, and clinical guidelines." In our view, inclusion of health policy as part of the core medical school curriculum is promising and can do much for the need to bring medical student input into the public eye. ${ }^{9}$ Our research expands upon this curriculum by reflecting upon the application of taught material in day-to-day health policy roles.

Reflecting upon the existing curriculum and what we witnessed during the junior doctor contract changes, we wanted to take these observations a step further and assess how medical students felt about being involved in a health policy role.

We conducted a cross-sectional survey among medical students on their involvement in health policy with the aim of gathering the following data:

1. Medical students' beliefs about their own current knowledge of health policy, and their desire to learn more about the topic.

2. Medical students' current or past involvement in a health policy role and whether they would like to be involved in health policy-making processes in their future careers.

3. Medical students' own perceived barriers to involvement in health policy roles whilst at medical school.

The GMC's outcomes for graduates is intended as a guide to train competent junior doctors; ${ }^{8}$ our questions can address gaps in knowledge of health policy roles amongst medical students, thereby contributing to a bigger discussion on health policy: could one foresee a generation of equipped medical students undertaking health policy roles?

\section{Methods}

An anonymized cross-sectional survey consisting of eleven questions was distributed using an online platform to recruit current medical students of any year or institution within the UK (Figure S1). Participants were recruited via convenience sampling, by word of mouth and referral strategies. Identification of a 24-hour period in which no responses were elicited warranted closing the survey. This amounted to approximately 5 days. Participants who identified themselves as current students studying at a medical institution within the UK were eligible. An anonymous online approach was adopted to protect participants and allow for as many responses as possible from a diverse number of regions. Medical education ethics committee approval for the project was granted by Imperial College London, and informed consent was obtained from participants. 


\section{Outcomes}

To minimize differences in individuals' understanding of health policy, the WHO definition was stated at the top of the questionnaire.

A rating scale of 1-5 was used to assess individuals' current knowledge of health policy. Closed questions identified: whether participants would like to be taught health policy in medical school; whether they believe that compulsory teaching on health policy should form part of the curriculum; whether they were or had been involved in a health policy role and whether they would consider undertaking health policyrelated work within their future career. Multiple responses were used to identify when students felt the best time to teach health policy should be and possible factors which may have prevented students from getting involved in a health policy committee role. A voluntary open question identified ways in which students believed they could contribute to the health policy-making process.

\section{Results}

A total of 120 medical students from seven different institutions responded. Six entries from participants outside of the UK were excluded. Two entries were excluded due to duplication. Overall, 112 responses from six institutions across the UK were therefore analyzed (Figure S2).

Students from each year of medical school were represented with the majority in their 4th year of study $(31 \%$, $35 / 112$; Figure 1). Of the sample studied, $47 \%$ (53/112) reported previous teaching on health policy within medical school - with the majority scoring themselves 2 out of 5 on the scale for knowledge about the topic $(38 \%, 43 / 112)$. However,

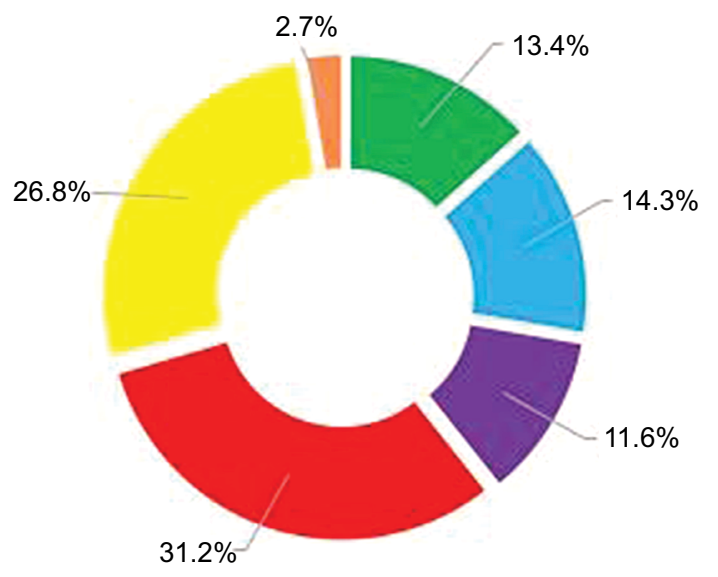

" Year 1 " Year 2 " Year 3 " Year $4 \quad$ Year 5 "Year 6

Figure I Graph showing breakdown of survey respondents by year of medical school.
$79 \%$ of participants (88/112; Figure 2 ) would like to be taught health policy at medical school, while $73 \%(82 / 112)$ believed that compulsory teaching on health policy should form a core part of the curriculum. Amongst year four and five students, third year was cited as the ideal time in which to be taught.

Ninety-six percent of participants (108/112) reported no current or previous activity in a health policy role - with $61 \%$ $(68 / 112)$ willing to undertake a health policy role in the future (Figure 2). The three biggest barriers for student involvement in a health policy role included a lack of knowledge about health policy (64/112), an unawareness of opportunities available (63/112) and a lack of time (48/112) (Figure 3). Themes emerging from an open-ended question into ways medical students believe they can contribute to health policy included the following: providing an unheard perspective, advocacy work, reforming health policy education, further research into health policy, personal development, as well as shaping future clinical practice.

\section{Discussion}

Our findings highlight that the overwhelming majority of medical students have had no participation in a health policy role. Addressing the reported barriers to involvement could be the key to facilitating greater medical student participation.

Health policy has become an important field within medicine. There is an increasing recognition of the role that economic, political and social policies have within medicine, and as trainees we should be involved in policies that affect the determinants of health. ${ }^{10}$ The inconsistency between $73 \%$ of our survey participants agreeing with mandatory teaching on health policy and health policy being listed as a core competency in the GMC's outcomes for graduates could be due to a number of reasons which would require greater exploration. For instance, this could reflect upon students' belief they cannot impact health policy or perhaps missed understanding of learning outcomes from teaching sessions.

Interestingly, although opportunity for further study is rooted in postgraduate academia, the study of health policy originates from vocational learning. ${ }^{11}$ There has been an increased call for a formalized curriculum providing essential training in health policy for future doctors. ${ }^{11}$ There has also been greater recognition of the void particularly in undergraduate education which in the UK has since been addressed. ${ }^{7}$ Whereas formalized teaching in health policy is now achieved through undergraduate means, as our survey suggests, perhaps the same attentive focus on providing opportunities for practical application of such modules has not been implemented. Interestingly, $96 \%$ of students in 


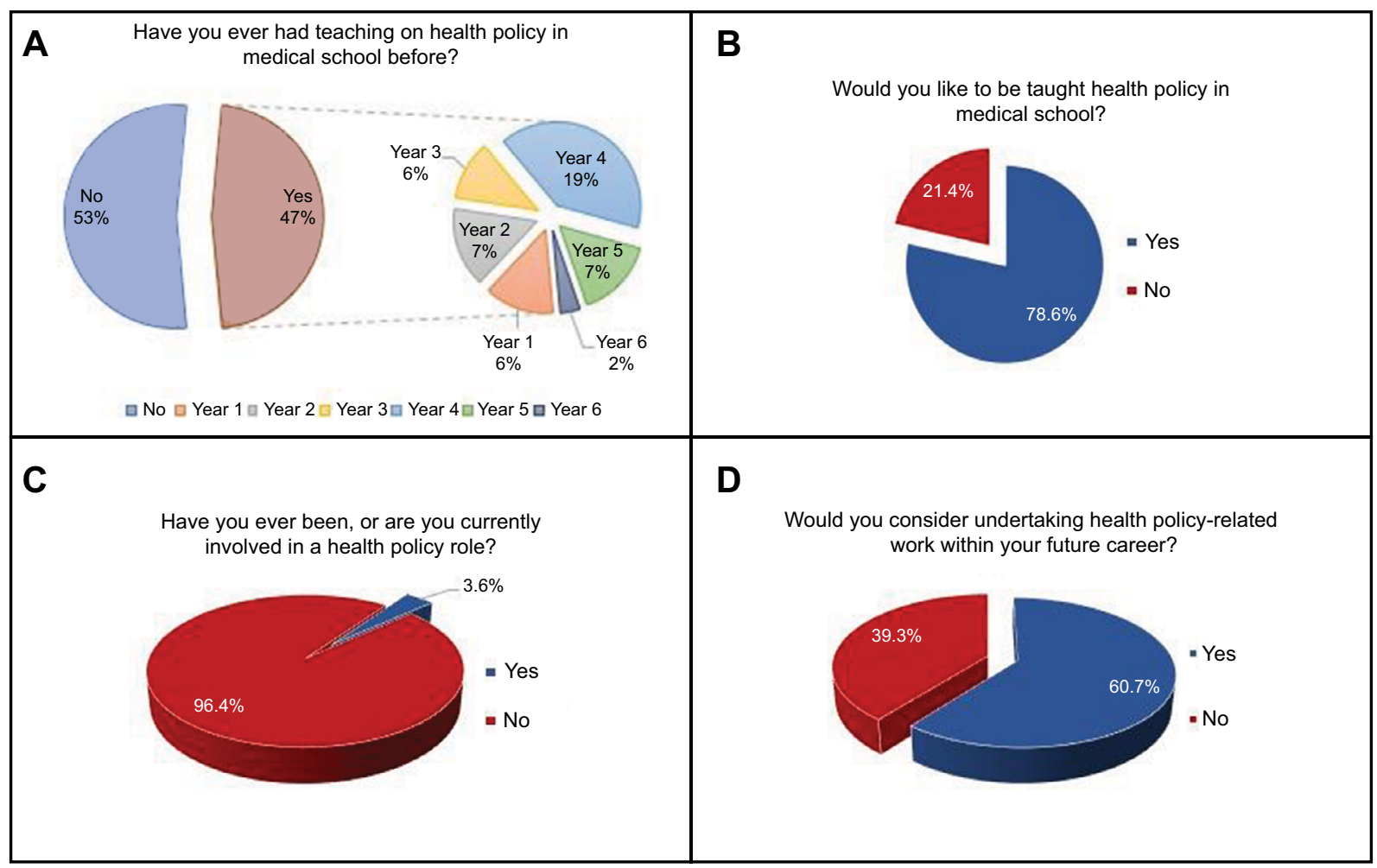

Figure 2 Status of health policy education within medical school $(\mathbf{A})$, student desire to study the subject (B), student involvement in a health policy role (C) and desire to undertake a health policy committee role in future (D).

our research had not been involved or were not currently involved in a health policy role, although the majority, $61 \%$, would consider undertaking health policy work in their future career (Figure 2). Although established learning objectives have been set by the GMC, addition of practical programs by medical schools to allow individuals to implement skills may be of benefit. If incorporated into the university program, such a scheme would allow students to partake in health policy committee roles and would be of benefit in tackling barriers to involvement. As identified through our survey, barriers to involvement in health policy include: lack of time, an unawareness of opportunities and the belief that students cannot affect health policy (Figure 3).

"Service learning" is a recognized approach within health policy education. ${ }^{12}$ This involves students participating in community-level service using principles learnt in formal academic programs. ${ }^{12}$ Given that teaching in medical school should already be well established with set learning outcomes, introducing a community activity could provide a choice of enrichment experiences. The question of whether formal lecture-based teaching time should be reduced in order to include the practical aspect would require greater discussion. Interestingly, a study by Patel et a ${ }^{13}$ found that students who received an intensive course on health systems self-reported three to four times greater perception as appropriately trained compared to those with a lower intensity course.

An example of a scheme at a community level suggested by the RCGP report ${ }^{7}$ is shadowing general practitioners who treat migrants. Relating this back to the example of a patient journey, this would allow medical students to think about how health policy could be adapted for those who are mobile and have discontinuity of care. This would be particularly relevant in addressing mental health, where migrants have an increased risk of disorders. ${ }^{14}$ Undertaking this communitybased experience while in a clinical year would allow for reflection on the differing needs of patient groups within a population. When analyzing results of the individuals in years 4 and 5 who have had at least a year's worth of clinical experience, year 3 is seen as the most appropriate time to introduce health policy teaching.

With a well-established program of service learning, one could foresee the benefit of participation on a global scale. The student elective already provides a great opportunity for individuals to gain experience in an underdeveloped country and this is endorsed by a number of grants support- 


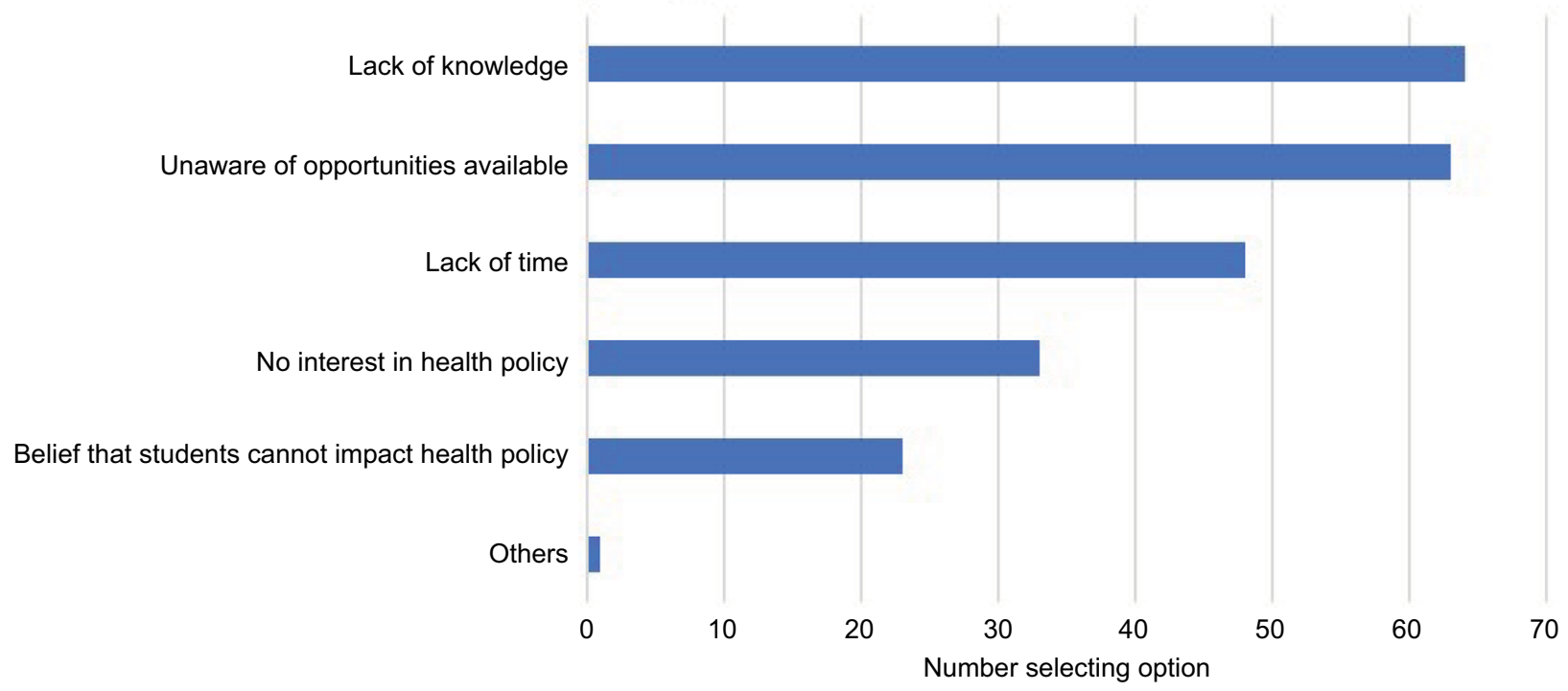

Figure 3 Factors preventing student involvement in a health policy committee roles.

ing travel expenses. The reflective log of students who have taken part in such an experience has two applications. The first is in enhancing the health policy syllabus with which younger medical students here in the UK are taught. The use of case studies in health policy training has been found to be a valuable method of learning, ${ }^{15}$ and as students we have personally found this an interactive approach. Secondly, it is interesting to note that although institutions teaching health policy exist across every WHO region in areas such as the Middle East and Latin America, Central and Eastern Europe had little relevant training and North Africa had none. ${ }^{16}$ Offering an exchange program between two institutions with a health policy-focused element would allow for individuals to develop their interest in the topic. In the long term, it is not unfeasible to visualize greater representation of residents from underdeveloped populations partaking in health policy-making processes that affect their own health system in partnership with global organizations. Having reflected upon the benefits of a hospital placement in an underdeveloped country, we have a much greater appreciation for the multitude of cultural, religious and social factors that need to be acknowledged before implementing a health program.

Emil et $\mathrm{al}^{17}$ evaluated student attitude and knowledge regarding health care policy and systems in Ontario and California and similarly found that there was a deficiency in health care policy teaching within medical school. Interestingly, our study reflects student opinion across several different institutions, but this is based on student experiences within the National Health Service (NHS). By studying two medical student cohorts who have experience in differing health systems, Emil et al ${ }^{17}$ have been able to comment upon student attitudes to universal health care. With the NHS currently facing a dynamic and challenging environment, longitudinal research into student attitudes towards the changes in the NHS would provide valuable data. Does being politically aware of medical student reforms stimulate student interest in health policy, and if so, is the medical school curriculum fluid enough to incorporate teaching based upon changing student interest? Further research into which factors facilitate a health policy curriculum that can continually evolve over time would be of value for medical educators and build upon findings from this study.

Our cross-sectional survey provides an insight into the desire of medical students to be involved in policy-making roles, and our own experiences have acted as a prompt for us to contribute to the growing discussion in this area. Our survey has some limitations. Firstly, our sample size is not representative of the whole medical student community, with some institutions being disproportionately represented compared to others. Secondly, although responses from each year of medical school were received, participants were not equally represented across all medical student years, with the majority in their 4th year of education. Furthermore, we acknowledge that our survey may be affected by selection bias, although 33 students reported no interest in health policy (Figure 3 ). Our survey would be strengthened by 
having a larger and more homogenous sample of students, which would facilitate further sub-analysis of findings. This could be achieved by disseminating the survey via medical school centralized mailing lists. Our survey did not intend to assess student satisfaction with teaching in medical school.

\section{Conclusion}

Our survey has highlighted that current medical student involvement in health policy roles is limited. We have touched upon the role of medical students and medical education in health policy, and potential avenues of increasing student confidence in their ability to undertake a health policy role while at medical school. Increasing evaluation and reform of current health policy curricula alongside a greater focus by individual medical schools on organizing and promoting health policy roles can only be of benefit in fulfilling students' desire to be involved in real-life health policy making. Greater medical student representation in policy-making processes could be key to achieving more informed decision making. Going forward, a generation of medical students equipped with core training in health policy and enriching practical experience will stand global health in greater stead.

\section{Disclosure}

The authors report no conflicts of interest in this work.

\section{References}

1. World Health Organisation. Health Policy; 2016. Available from: http:// www.who.int/topics/health_policy/en/. Accessed October 19, 2017.

2. Souliotis K. Public and patient involvement in health policy: a continuously growing field. Health Expect. 2016;19(6):1171-1172.

3. General Medical Council. Patient and public involvement in undergraduate medical education; 2011. Available from: http://www.gmc-uk.org/ Patient_and_public_involvement_in_undergraduate_medical_education_guidance_0815.pdf_56438926.pdf. Accessed October 19, 2017.
4. Mukohara K, Ban N, Sobue G, Shimada Y, Otani T, Yamada S. Follow the patient: process and outcome evaluation of medical students' educational experiences accompanying outpatients. Med Educ. 2006;40(2): 158-165.

5. The Independent. More than 7,000 medical students pledge support for junior doctors ahead of beginning of industrial action in England; 2016 [cited April 2, 2017]. Available from: http://www.independent. co.uk/student/news/more-than-7000-medical-students-pledge-supportfor-junior-doctors-ahead-of-beginning-of-industrial-a6805991.html. Accessed October 19, 2017.

6. Siddiqui S, Hossain I, Siddiqui S, et al. Medical students' views on the new junior doctor contract. BMJ. 2016;532:i282.

7. Royal College of General Practitioners. A Core Curriculum for Learning about Health Inequalities in UK Undergraduate Medicine; 2013. Available from: https://goo.gl/WSZ4rY. Accessed October 19, 2017.

8. General Medical Council. Outcomes for Graduates. Available from: http://www.gmc-uk.org/education/undergraduate/undergrad_outcomes. asp. Accessed October 19, 2017.

9. Powers BW, Jain SH. Youthful critics: the medical student voice in health reform. Acad Med. 2015;90(1):3.

10. Gupta R. Why should medical students care about health policy? PLoS Med. 2006;3(10):1696-1698.

11. Riegelman R. Commentary: health systems and health policy: a curriculum for all medical students. Acad Med. 2006;81(4):391-392.

12. Cohen S, Milone-Nuzzom P. Advancing health policy in nursing education through service learning. ANS Adv Nurs Sci. 2001;23(3): $28-40$.

13. Patel MS, Davis MM, Lypson ML. Advancing medical education by teaching health policy. $N$ Engl J Med. 2011;364(8):695-697.

14. World Health Organisation Regional Office for Europe. Migrant populations, including children, at higher risk of mental health disorders. Available from: http://www.euro.who.int/en/health-topics/ noncommunicable-diseases/mental-health/news/news/2017/04/ migrant-populations,-including-children,-at-higher-risk-of-mentalhealth-disorders. Accessed October 19, 2017.

15. Heiman HJ, Lerissa Smith L, McKool M, Mitchell DN, Bayer CR. Health policy training: a review of the literature. Int $J$ Environ Res Public Health. 2015;13(1):1-12.

16. Tancred TM, Tancred TM, Schleiff M, Peters H, Balabanova D. Health policy and systems research training : global status and recommendations for action. Bull World Health Organ. 2016;94(7):491-500.

17. Emil S, Nagurney JM, Mok E, Prislin MD. Attitudes and knowledge regarding health care policy and systems: a survey of medical students in Ontario and California. CMAJ Open. 2014;2(4):E288-E294. 


\section{Supplementary materials}

\section{Medical Students in Policy Making}

We are conducting a short survey on medical students in policy making and would be grateful if you could fill this short survey.

By filling out this survey I agree that I am happy for my responses to be anonymously included in the final report for publication and am happy that the anonymised data will be stored confidentially for six years

$\sqcup$ I agree

Definition of Health Policy

WHO definition: "Health policy refers to decisions, plans, and actions that are undertaken to achieve specific health care goals within a society. An explicit health policy can achieve several things: it defines a vision for the future which in turn helps to establish targets and points of reference for the short and medium term. It outlines priorities and the expected roles of different groups; and it builds consensus and informs people"

What Medical School are you in? *

Short answer text

What Year of Medical School are you in? *
Year 1
Year 2
Year 3
Year 4
Year 5
Year 6

Have you ever had teaching on health policy in medical school before? *
Yes
No

How much do you know about health policy *

$\begin{array}{ccccccc} & 1 & 2 & 3 & 4 & 5 & \\ \text { Nothing } & 0 & 0 & 0 & \bigcirc & \bigcirc & \begin{array}{c}\text { Very } \\ \text { knowledgable } \\ \text { about the topic }\end{array}\end{array}$

Would you like to be taught health policy in medical school? *
Yes
No

Figure SI (Continued) 
Do you think all medical students should receive compulsory teaching on health policy as part of the curriculum?

Yes

No

If introduced, which year of medical school do you think teaching on health policy should be?
$\square$ Year 1
Year 2
Year 3
Year 4
Year 5
Year 6
Any year
$\neg$ All years

Have you ever been, or are you currently involved in a health policy role? *

Yes

No

Would you consider undertaking health policy related work within your future * career?

Yes
No

Which of the following prevent you from getting involved in a student health * policy committee role? (you can select one or more options)

$\square$ Lack of time

$\square$ Lack of knowledge about health policy

$\square$ No interest in health policy

Unaware of opportunities available

The belief that students cannot impact health policy

Other...

In what ways do you think medical students could help in the health policy making process?

Long answer text

Thank You for filling out our survey!

Figure SI Questionnaire distributed to students via online platform.

Note: An asterisk indicates that a question is compulsory. 
Total number of responses: 120

Responses outside of the UK excluded: 6

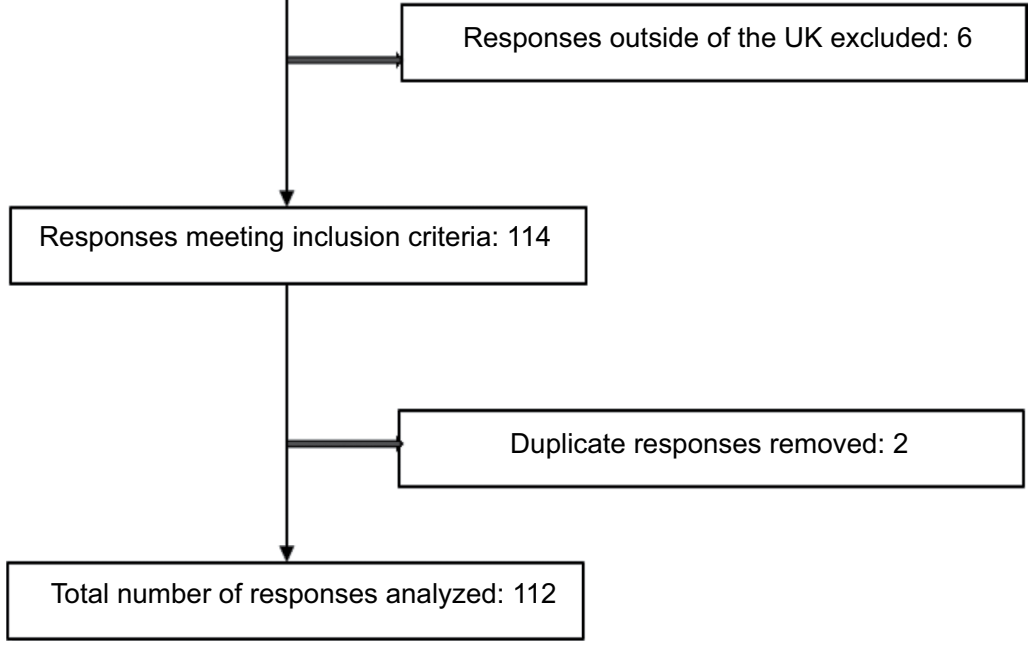

Figure S2 Schematic of data inclusion.

\section{Publish your work in this journal}

Advances in Medical Education and Practice is an international, peerreviewed, open access journal that aims to present and publish research on Medical Education covering medical, dental, nursing and allied health care professional education. The journal covers undergraduate education, postgraduate training and continuing medical education including emerging trends and innovative models linking education, research, and health care services. The manuscript management system is completely online and includes a very quick and fair peer-review system. Visit http://www.dovepress.com/testimonials.php to read real quotes from published authors.

Submit your manuscript here: http://www.dovepress.com/advances-in-medical-education-and-practice-journal 